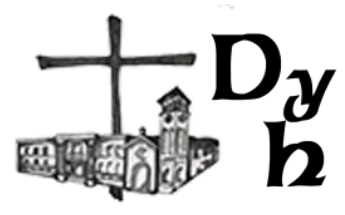

Tres miradas sobre Leonardo filósofo

Prof. Adriana Rogliano

Dios y el hombre, vol. 4, n. 1, e052, 2020

ISSN 2618-2858 - https://doi.org/10.24215/26182858e052

https://revistas.unlp.edu.ar/DyH/index

Cátedra libre de pensamiento cristiano - UNLP

Seminario Mayor San José

La Plata, Buenos Aires, Argentina

\title{
TRES MIRADAS SOBRE LEONARDO FILÓSOFO
}

Three Looks on Leonardo Philosopher

\author{
Prof. Adriana Rogliano \\ arogliano@gmail.com \\ Investigadora independiente - La Plata - Argentina
}

\section{Resumen}

La figura de Leonardo, según el ideal renacentista del homo universalis, admiró y sigue sorprendiendo a los que se le acercan. Un halo de misterio le envuelve. La escasa producción artística contrasta con la abundancia de las observaciones, e invenciones. Sus cuadernos de apuntes testimonian la multiplicidad de sus intereses. Los historiadores del arte, de la ciencia y de la filosofía han hecho de sus fecundas investigaciones objeto de estudio. Así es como se tornó un mito. No sin razón se ha planteado la pregunta: "¿fue Leonardo esencialmente artista, científico o filósofo?" Se ocuparon de Leonardo, Vasari, su primer biógrafo, y luego Goethe, Winckelmann, Burkhard, Valery... Exponemos aquí tres enfoque de la cuestión propuestos por Benedetto Croce, Giovanni Gentile y Karl Jaspers, precedidos por un esbozo biográfico y concluyendo con la semblanza que de Leonardo traza nuestro poeta Leopoldo Lugones.

Palabras claves: Leonardo filósofo, ojo, conocimiento.

\section{Abstract}

The figure of Leonardo, according to the Renaissance ideal of homo universalis, admired and continues to surprise those who approach him. A halo of mystery surrounds him. The scarce artistic production contrasts with the abundance of observations and inventions. His notebooks bear witness to the multiplicity of his interests. Historians of art, science and philosophy have made their fruitful research a subject of study. This is how it became a myth. Not without reason has the question been asked: "Was Leonardo essentially an artist, scientist, or philosopher?" They dealt with Leonardo, Vasari, his first biographer, and then Goethe, Winckelmann, Burkhard, Valery. We present here three approaches to the question proposed by Benedetto Croce, Giovanni Gentile and Karl Jaspers, preceded by a biographical sketch and concluding with the portrayal that our poet Leopoldo Lugones evokes of Leonardo.

Keywords: Leonardo philosopher, eye, knowledge.

Recibido: 16/05/2020

Aceptado: 18/05/2020

Publicado: 24/06/2020 


\section{Circunstancias vitales}

Mucho se ha especulado acerca de Leonardo, su personalidad, conocimiento y actividad heterogénea.

Veamos un poco de historia.

Anota su abuelo paterno:

1452 Nació mi nieto, hijo de ser Piero ${ }^{1}$, mi hijo, el día 15 de abril, sábado, por la noche. $^{2}$ Se le puso de nombre Leonardo. Lo bautizó el padre Piero di Bartolomeo da Vinci. $^{3}$

Fruto de los amores de ser Piero —casado poco tiempo después-y de la campesina Caterina —dada en matrimonio ulteriormente-, la infancia de Leonardo se desarrolló en Vinci entre estos dos polos familiares. Una anotación catastral hecha a los cinco años y otra a los diecisiete dan cuenta de su condición de ilegítimo lo cual le imposibilitaba recibir la formación propia de los miembros de su familia. Lo único que sabemos es que su padre le envió a una escuela de música y de gramática, para aprender a tocar la flauta y a escribir.

Más adelante, ser Piero, al comprobar las dotes del niño Leonardo para el dibujo, decidió ofrecerlo como aprendiz al renombrado artista Andrea del Verrocchio quien tenía una importante bottega en Florencia. Y allí se trasladó Leonardo, a la muerte de su abuelo, hacia 1465. Bajo la guía del Verrocchio se familiarizó con diversas artes, a la vez que se contactaba con la gente ilustrada de la ciudad.

Lo cierto es que entre 1469 y 1472 Leonardo se inscribió en la Compañía de San Lucas, ${ }^{4}$ la corporación de los pintores florentinos, aunque sin romper los lazos con el taller del maestro. Comenzó así su vida profesional, marcada, como era usual, por la competitiva búsqueda de encargos y la cortedad de los plazos de entrega. En 1477 Leonardo abre su propio taller. Es el mismo año en que se inicia la relación con Lorenzo de Medici, concluida con la muerte de Giuliano de Medici.

\footnotetext{
${ }^{1}$ Pertenecía a una familia de notarios que se remontaba al siglo XIII.

${ }^{2}$ Según el calendario gregoriano: el 23 abril a las 21.40 .

${ }^{3}$ Nascita di Leonardo. Florencia, Archivio di Stato. Notarile antecosimiano, 16912, f. 105v. Recuperado de http://www.bne.es/es/Micrositios/Exposiciones/Leonardo/resources/img/Capl_part2.pdf

${ }^{4}$ Gremio de pintores que, entre 1339 o 1449, fue autorizado a funcionar independientemente del de médicos y farmacéuticos, del que hasta entonces formara parte.
} 
Se registran por aquel tiempo importantes trabajos pictóricos. ${ }^{5}$ A pesar de todo ello, Leonardo y su padre se muestran insatisfechos.

Leonardo sueña con Milán. Algunos autores mencionan una cierta discrepancia con el clima del neoplatonismo reinante en Florencia y las simpatías de Leonardo por el aristotelismo que predominaba en el norte. ${ }^{6} 7$

Para acceder a un puesto en los dominios de los Sforza, hizo componer una laudatio muy bien escrita, dirigida a Ludovico el Moro, en donde se presenta como ingeniero militar, arquitecto $y$, finalmente, escultor y pintor. $Y$ es que la actividad artística aún no detentaba el prestigio que alcanzaría en el siglo siguiente.

Entre 1482 y 1499, transcurre la primera estadía en Milán. Leonardo contaba entonces treinta años y permanecería en la ciudad ducal por diecisiete. Fue un lapso de intensa actividad.

En la corte milanesa gozó de un amplio reconocimiento por parte del duque Ludovico y recibió significativas compensaciones, como la donación de un extenso viñedo, sito en Porta Vercellina (barrio residencial en las afueras de Milán). En el acta de donación se lee:

El duque de Milán, etc. [dona una extensa viña] a Leonardo Vincio florentino, pintor celebérrimo, el cual no cede en mérito a ningún otro pintor, ni de la antigüedad ni de nuestro tiempo, incluso a juicio de los ciudadanos más expertos (Milán, Archivio di Stato. Autografi, doc. 102, f. 34r).

La casa contaba con un cuarto privado para estudiar y meditar, un estudio que solamente poseían las gentes ilustradas y de buen pasar. Lo prueba una de sus notas de 1494 referida a la colocación de una cerradura en su studiolo.

\footnotetext{
${ }^{5}$ La Anunciación (1443-74); el Bautismo de Cristo, colaborando con el Verrocchio (1475-76); la Virgen de la flor (1475-76) el Retrato de Ginevra de'Benci (1476-78); la Madonna Benois (1479-80); la Adoración de los Magos (1481).

${ }^{6}$ Entre ellos E. Grassi, I. Blashka, y si atendemos los varios títulos de Aristóteles presentes en la biblioteca de Leonardo.

${ }^{7}$ Fue importante la presencia del helenista de Constantinopla conocido como Giovanni Agiropulo que tradujo Aristóteles al latín y enseñó en Florencia entre 1456-1472.
} 
Hacia 1495, llega a manos de Leonardo una copia del libro Summa de arithmetica, geometria, proportioni et proportionalita de Luca Pacioli (14451519), un franciscano conventual afamado matemático y profesor universitario ${ }^{8}$. Según apunta el Dr. Fernando Blasco, se trataba de una “gran labor de recolección, sistematización y difusión de las matemáticas que se conocían al principio del Renacimiento" que "puede perfectamente considerarse como un libro de texto" y que, como el mismo autor reconocía, contenía las "ideas de grandes matemáticos como Euclides, Boecio, Sacrobosco y Fibonacci" (F. Blasco, 2019). Dado el empeño de modernización de Milán, Leonardo le sugirió al duque Ludovico que le invitara a la corte. Pacioli aceptó y en 1496 ocupó la primera Cátedra de Matemáticas de Milán. Podemos conocerlo por la pintura que lo representa impartiendo clase, datada en 1495 y atribuida no sin discusión - al veneciano Jacopo de Barbari (algunos piensan que el poliedro de cristal del ángulo superior habría sido pintado por el mismo Leonardo).

De intercambio mutuo surgieron varios proyectos literarios de fray Pacioli que serían ilustrados por Leonardo: De divina proportione (Sobre la divina proporción); De Viribus quantitatis (Sobre el poder de los números) y De ludo scacchorum (El juego del ajedrez) ${ }^{9}$. Era el tiempo en que la matemática aparecía como base del arte y la ciencia.

A esta etapa pertenece La Última Cena (c. 1495-1498) realizada en el refectorio del convento dominico de Santa Maria delle Grazie, sede elegida por Ludovico para que fuese iglesia y mausoleo de la familia Sforza. Con esta notable creación, Leonardo inaugura un nuevo lenguaje pictórico y una técnica alla maniera moderna. Los pintores Giovanni Antonio Boltraffi o y Marco d'Oggiono ya trabajaban a las órdenes del maestro florentino.

Simultáneamente, se le encarga a Leonardo la decoración de un salón situado en la planta baja de la torre noreste del Castello sforzesco. El resultado será la decoración de la llamada: Sala delle Asse (concluida en 1498), una pintura

\footnotetext{
${ }^{8}$ Toscano de nacimiento había estudiado matemática en Venecia. Se trasladó a Roma con Leon Battista Alberti, secretario papal. En Roma se formó en teología para, finalmente, profesar como franciscano. Fue lo que se traduciría hoy día como "contador y economista" a quien se deben las bases de contaduría moderna, autor de una Summa en que recoge y sistematiza los aportes de Euclides, Boecio, Sacrobosco y Fibonacci. Enseñó en diversas universidades de Italia.

${ }^{9}$ Libro que no se publicó y se creyó perdido, siendo descubierto, en diciembre de 2006, en la biblioteca veneciana.
} 


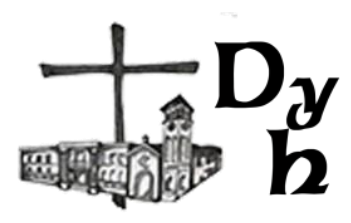

mural monocromática simulando una pérgola con hojas y ramas florecidas de dieciocho moreras que se entremezclan entre sí, una compleja alegoría referida al duque Ludovico quien, desde 1490, había adoptado como símbolo aquel árbol. ${ }^{10}$ El entorno vegetal tupido también exhibe un variado paisaje sobre el que resplandece el escudo heráldico de los Sforza, según se descubrió durante la última restauración (2013-2019). La decoración también parece aludir a la alianza celebrada en 1491 entre la dinastía de los Sforza y la de los d'Este mediante el matrimonio entre Ludovico Maria y Beatrice. ${ }^{11}$

Un hecho político desbarata la actividad de Leonardo: el rey de Francia, Luis XII —descendiente de los Visconti, antiguos señores milaneses — reclama el ducado de Milán, iniciando una larga campaña militar.

Leonardo decide abandonar Milán. Se inicia un nuevo ciclo en su ajetreada vida.

El período itinerante (1499-1508)

Junto con Fray Pacioli y otros acompañantes, Leonardo parte a Mantua. Allí esbozará el retrato de la Marquesa Isabel d'Este (1500). Al año siguiente va a Venecia. En el verano de 1502, entrará al servicio de Cesar Borgia, duque de Valentinois (1475-1507), para la campaña militar de Romagna. Con fecha 18 de agosto de ese mismo año, se le expide un salvoconducto en el que se especifican las funciones que desarrollará Leonardo: la inspección de las plazas y fortalezas de sus estados.

Comenzó entonces un ir y venir entre Florencia y Milán.

Leonardo aun intenta realizar algunos encargos como ingeniero. Merece especial mención el diseño de un puente de 346 metros que debería unir Estambul y Gálata, sobre el Cuerno de Oro. Este proyecto aparece brevemente descripto en un cuaderno fechado entre 1502 y 1503. El destinatario del mismo era el sultán Bayaceto II, quien deseaba sustituir la construcción provisional

\footnotetext{
${ }^{10}$ Origen del apelativo 'el Moro' con que se lo conocerá.

11 La sala, tras la derrota del duque, se había convertido en caballeriza de los sucesivos ejércitos invasores. La pintura fue descubierta accidentalmente en el siglo XIX y recuperada tras la segunda guerra mundial.
} 
existente sobre el Cuerno de Oro por otra permanente. La propuesta, a pesar del interés que mostraba el gobernante turco, no llegó a materializarse. El proyecto de Leonardo era, sin duda, demasiado avanzado para su tiempo. ${ }^{12}$

Segunda etapa florentina (1503-1506)

En marzo de 1503, después de la caída el poderoso condottiero César Borgia, Leonardo se encontraba de regreso en Florencia y parece haber permanecido allí por tres o cuatro años. En los primeros meses de este período, con el dinero ganado en aquellas campañas militares, decide comprar una bella finca rodeadas de olivos y árboles frutales, de media hectárea de extensión, ubicada en Fiesole.

Atraído por la noticia de un posible e importante encargo pictórico, Leonardo se registra de nuevo en la Compagnia di San Luca. En efecto, la Signoria de Florencia proponía la realización de dos grandes murales para la Sala del Consejo (actualmente sala del Cinquecento) en el Palazzo Vecchio. Se trataba de la representación de dos temas patrióticos tomados de los anales de la República: la batalla de Cascina, librada en guerra contra Pisa (1364) y la victoria de Anghiari sobre los milaneses (1440).

El primer tema fue confiado a Miguel Ángel y el segundo a Leonardo. Cada uno de los artistas propuso un motivo que consideraba representativo de los respectivos hechos bélicos. Miguel Ángel eligió el momento en que los florentinos, que se estaban refrescando en el Arno, fueron avisados de la proximidad de los pisanos, y Leonardo optó por la violenta refriega causada por la posesión del gonfalone (estandarte) florentino.

Así fue como en el mes de octubre de 1503, con el fin de que dispusiese de espacio suficiente para trabajar en los bocetos y el gran cartón previo, a Leonardo le fueron confiadas las llaves de la Sala del Papa, situada en el claustro

\footnotetext{
12 La idea resurgió en 1995 cuando el arquitecto noruego Vebjorn Sand, tras visitar en Oslo una exposición de dibujos de ingeniería y arquitectura de Leonardo, queda deslumbrado por el diseño de aquel puente. Por iniciativa de dicho artista, quien coordinó a ingenieros y arquitectos, un puente peatonal de 100 metros de largo y ocho de alto, fue construido, según diseño de Leonardo, en Aas (Noruega) e inaugurado por la Reina Sonja, en noviembre de 2001. Por otra parte, el 17 de mayo de 2006 se anunció que el primer ministro turco y el alcalde de Estambul habían decidido reactivar el proyecto del puente de Leonardo da Vinci. Los estudios de viabilidad y planificación del proyecto habían comenzado ya a principios de 1999.
} 


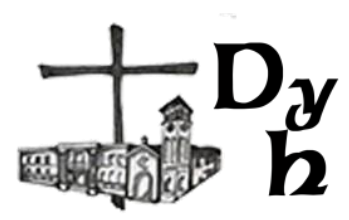

de Santa Maria Novella, y se le habilitó un aposento contiguo. Según consta en documento de 1504, siendo Canciller Nicolás Maquiavelo. ${ }^{13}$

La muestra de los cartones preparados por cada uno de los pintores de efectuó en 1505. Fue un acontecimiento cultural de envergadura. Toda la juventud del mundo artístico se apresuró a copiarlos. Ambas obras todavía existían en el siglo XVIII; y no se sabe cuando desaparecieron. La composición de Leonardo se conoce por una copia realizada por Rubens, y la de Miguel Ángel, por un famoso grabado de Marcantonio Raimondi.

Leonardo, que por su propia forma de trabajo no gustaba del fresco, imaginó un procedimiento de encausto al modo de los antiguos. Esta técnica utiliza la cera como aglutinante y necesita de un pulido final, tal como Plinio el Viejo y Vitruvio la describieron. ${ }^{14}$

El tamaño y posición de la escena sobre la pared había exigido la fabricación de una especie de andamiaje que le permitiese trabajar y moverse con facilidad. Giovanni Cellini, —el padre de Benvenuto-, contribuyó a la realización de una especie de andamiaje, ideado por el maestro, que le permitiese trabajar y moverse con facilidad. El encargo de la Batalla de Anghiari implicó una actividad intensa. Leonardo ejecutó su trabajo con ardor durante meses, pero, no faltaron percances.

Una nota en el Codex Madrid II describe el fenómeno atmosférico acontecido mientras Leonardo daba las primeras pinceladas de color a su obra

El día 6 de junio de 1505, viernes, al toque de las 13 horas, empecé a dar el color en Palacio. Tan pronto como dejé el pincel, el tiempo se estropeó y en ese instante sonó la campana que convocaba a los hombres ante el tribunal. El cartón se rompió, el agua se vertió y se quebró el recipiente que la contenía. En

\footnotetext{
13 "Es sabido [...] que hace unos meses Leonardo di ser Piero da Vinci, ciudadano florentino, se ha comprometido a pintar una superficie rectangular de la Sala del Gran Consejo. Como haya sido comenzada ya tal pintura sobre un cartón por el citado Leonardo y haya percibido por ese concepto 35 florines de oro en oro, los magníficos señores [representantes de la autoridad] desean que tal obra sea llevada a término lo más pronto posible y que le sea abonado al citado Leonardo en ciertas ocasiones alguna suma de dinero [...] y determinaron que el dicho Leonardo deberá haber concluido por completo de pintar el dicho cartón y llevarlo al máximo grado de perfección dentro del próximo mes de febrero de 1505". Florencia, Archivio di Stato. Signori e Collegi. Deliberazioni in forza di ordinari autorità, 106, f. 40r.

${ }^{14}$ Técnica ampliamente utilizada por los romanos y bizantinos. Las tablas de Al-fayun son buena muestra de ello.
} 
un momento empeoró el tiempo y llovió torrencialmente hasta bien entrada la tarde. El resto del día se quedó como si fuese de noche (BNE Codex Madrid II, (Mss. 8936), f. 1r.).

Miguel Ángel, habiendo sido llamado a Roma, abandonó su trabajo en el Palazzo Vecchio. Y Leonardo, finalmente, se marchó de Florencia, agotado por las múltiples dificultades surgidas.

Además de incontables bocetos, solamente se ha conservado el grupo central de La batalla de Anghiari: el de los caballeros combatiendo ferozmente por la posesión del estandarte, registrado por un dibujo de Rubens (Louvre) y un grabado de Edelinck. Sin embargo, se ha dicho que, entre los siglos XVI y XVII, no hay obra en su género más importante que aquel diseño; las cacerías de Rubens y todas las de la escuela flamenca no serían más que variaciones y repeticiones de aquel furioso entrevero.

Pertenece al mismo período (1505, aproximadamente) el retrato de Madonna (Monna) Lisa, ${ }^{15}$ universalmente conocida como La Gioconda que, adquirido por Francisco I, fuera conservado por tres siglos en Fontainebleau. ${ }^{16}$ Leonardo dedicó cuatro años para plasmar ese rostro único. Vasari relata las precauciones que tomó Leonardo para divertir a su modelo durante las sesiones y mantener en sus labios aquella sonrisa casi imperceptible, con un ligero matiz de ironía florentina. ${ }^{17}$

Segunda etapa milanesa (1506-1513)

Leonardo y sus acompañantes regresan a Milán en junio de 1506. Consigo lleva el retrato inconcluso de Lisa Gherardini del Giocondo y un manuscrito sobre el vuelo de las aves.

15 El profesor Giuseppe Pallanti anunció, en 2007, que Lisa Gherardini (1479-1542), la modelo veinteañera, esposa del comerciante Francesco del Giocondo, habitó en una casa frente a la de la familia de Leonardo, en la florentina calle Ghibellina, y que su marido se relacionaba con el padre del artista.

16 Desapareció del Louvre, donde había estado desde 1793, el 21 de agosto de 1911. Una vez recuperada, se encuentra nuevamente en allí, donde se exhibe bajo una fuerte protección y detrás de un cristal a prueba de balas.

${ }^{17}$ El San Juan Bautista o Bacchus sentado en un paisaje es contemporánea de la Gioconda. Copias antiguas están en el Louvre y en Sant'Eustorgio, Milán. La Leda y el cisne es del mismo período en el Casino Borghese. La última pintura de Leonardo que poseemos es el espléndido boceto de San Jerónimo en el desierto de la colección del Vaticano y data de 1514. 
Goza allí de la protección del lugarteniente real, Charles d'Amboise, y de la corte francesa. En 1507, Luis XII lo define como nostre paintre et ingenieur ordinaire. Ese año también recupera los derechos sobre su viñedo de Porta Vercellina, que le había sido incautado e intenta solucionar por vía diplomática el conflicto por el contrato incumplido con la Signoria florentina, e inicia una compilación de textos dedicados a hidráulica y geología.

Leonardo conoce entonces a Giovan Francesco Melzi (1493-1572/3), un joven noble, que lo hospeda en la mansión familiar de Vaprio d'Adda, y quien, se convertirá en su fidelísimo discípulo.

Para los nuevos mecenas franceses Leonardo dirigió la representación escénica de la obra Orfeo, de Angelo Poliziano (1507), y organizó el desfile triunfal de Luis XII durante su entrada en Milán tras haber derrotado a los venecianos (1509).

Durante este período, a la par que se desempeñaba como artista de corte, concluía algunos cuadros iniciados en Florencia y proseguía con sus estudios sobre anatomía. "En este invierno de 1510 espero terminar toda la Anatomía", anotaba.

Ciertamente, aquí con 15 figuras completas te será mostrada la cosmografía [descripción] del microcosmos, siguiendo la misma planificación que fue adoptada por Ptolomeo en su Cosmografía, obra que he visto previamente. En consecuencia, dividiré así la figura humana: los miembros, al igual que él dividió el mundo en provincias; luego, indicaré la función de las partes en todos sus aspectos, poniendo ante tu vista una descripción de toda la fi gura en su forma y contenido [...] (Windsor Castle, Royal Library. The Windsor Collection, f. 19061r).

Su protector Charles d'Amboise falleció en 1511 y al año siguiente, los franceses, fueron derrotados y expulsados de Milán. Con la restauración de los Sforza la situación era incierta, Leonardo, en compañía de Giovan Francesco Melzi y su criado Salaì, se marcha de Milán con destino a Roma. 
Estadía en Roma (1514-1516)

Tras la elección como papa de León X -Giovanni di Medici, hijo de Lorenzo el Magnífico $^{18}$ - Roma se convierte en enclave mediceo. Leonardo, viejo conocido de la familia, es contratado por Giuliano de Medici - hermano del Papa y futuro duque de Nemours-, para desecar unas tierras pantanosas que poseía, ${ }^{19}$ rehacer el puerto de Civitavecchia y continuar pintando, alojado en el Belvedere del palacio apostólico.

Leonardo registra:

Acabado [un problema geométrico] el día 7 de julio [1514], a las 23 horas en el Belvedere, en el studiolo que me ha habilitado el Magnífico [Giuliano de Medici].

A comienzos de 1515 fallecía el rey de Francia Luis XII. Giuliano y su protegido Leonardo formaban parte del séquito del papa León $X$ en el viaje a Bolonia a fin de entrevistarse con el nuevo rey de Francia, Francisco I. El papa para en Florencia, con sus acompañantes, durante un mes. Y esta será la última vez que Leonardo resida en la capital toscana.

En Bolonia tuvo lugar un encuentro del monarca francés con Leonardo, quien fue invitado a instalarse en Francia prometiéndole magníficas condiciones.

Por desgracia, Giuliano de Medici —afectado de tuberculosis-, muere inesperadamente en 1516. El papa hace trasladar a Leonardo al Castel Sant'Angelo, donde continuará con sus estudios astronómicos y técnicos durante unos meses, pero su situación en Roma no dejaba de ser incómoda e inestable. "Los Medici me crearon y me destruyeron", anotará ese mismo año.

\section{Estadía en Francia (1516-1519)}

Finalmente Leonardo decidió aceptar el ofrecimiento del rey Francisco I para trasladarse a Francia. Y aunque ya contaba sesenta y cuatro años —edad avanzada para la época- se aprestó a cruzar los Alpes (posiblemente en la segunda mitad de 1516), afrontando el viaje más largo de su vida. Lo acompañaban su criado Salaì y el noble milanés Francesco Melzi. En su cuaderno anotó que debería encontrarse en Amboise, en el palacio de Cloux

\footnotetext{
${ }^{18}$ Rafael pintó su retrato, con el castillo de Ant'Angelo, al fondo, asomando detrás de un cortinado.

${ }^{19}$ Las Lagunas pontinas. Se retomó el trabajo en el s. XX.
} 


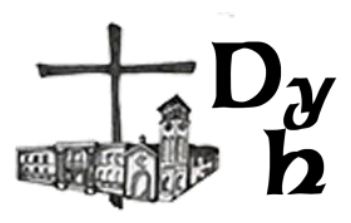

(actualmente Clos-Lucé), que el joven rey había puesto a su disposición, junto con una alta remuneración de mil escudos anuales. Leonardo, como pintor, arquitecto e ingeniero del rey, se comprometía a realizar proyectos para fiestas y torneos de la corte de Amboise.

En aquel ambiente Leonardo se sintió valorado como pintor y también como filósofo.

Según el relato de Antonio de Beatis, secretario del cardenal Luigi d'Aragona, quien le visitó en su paso por Amboise (10 de octubre de 1517), se infiere que Leonardo pueda haber padecido un ictus que la paralizara el lado derecho del cuerpo y que, dadas las dificultades para pintar, se dedicaba a organizar sus manuscritos y a enseñar a sus discípulos. El maestro le habría mostrado los escritos y tres cuadros: Santa Ana, San Juan Bautista y un retrato femenino.

De 1518 es una nota con que cierra una exposición de geometría con "etcétera", agregando "porque la sopa de verdura se enfría."

Por entonces, Salaì habría vendido al rey de Francia algunos cuadros, tras lo cual habría escapado a Milán.

Leonardo, se empeñaba aún en la canalización y el modo de controlar el recorrido del Loira haciéndolo navegable.

El 23 de abril de 1515, Leonardo dictó su testamento (actualmente perdido) al notario real Guillaume Borian. Nombró a "messer Francesco da Melzo" como albacea testamentario y le dejó todos los libros de su biblioteca, los utensilios de pintor; el resto de su pensión y sumas de dinero que le son debidas y todos los vestidos que posee. A nadie olvidó en el testamento: sus hermanos de padre, el jardinero, la criada, y hasta Salaì.

En la casa de campo de Cloux, Leonardo falleció, el 2 de mayo 1519, a los 67 años de edad, acompañado por su discípulo y secretario Francesco Melzi. Actualmente está sepultado en la capilla de San Huberto, en el Castillo Real de Amboise, a donde sus restos fueron trasladados en 1874, procedentes del claustro de la iglesia de Saint-Florentin, destruida durante la Revolución Francesa. 
En cumplimiento de su responsabilidad como albacea, Melzi notificó de lo acontecido a los parientes de Leonardo, recalcando que: "Fue para mí el mejor de los padres. Mientras conserve un hálito de vida en mi cuerpo sentiré la tristeza de su pérdida".

Los abundantes manuscritos de Leonardo fueron cuidadosamente conservados y se convirtieron en fuente de inestimable valor para las biografías que Vasari y Lomazzo compusieran. A él se debe la conservación del Tratado de la pintura y la copia de diversos dibujos del maestro florentino. Los descendientes de Melzi vendieron la colección y ésta se dispersó definitivamente. Tras una historia plagada de peripecias, lo que pudo rescatarse de esos escritos fue publicado en el siglo XVII. ${ }^{20}$

Es de destacar que Leonardo poseyó una surtida biblioteca compuesta por 150 volúmenes, cifra importantísima para la época, en las que figuraban obras de autores antiguos y modernos. Entre ellos se cuentan: Aristóteles (Problemas, Retórica, Proposicione), Euclides (Geometría), Esopo (en verso y otra en francés), Plinio, Ovidio, San Agustín (De la inmortalidad del alma, La ciudad

\footnotetext{
${ }^{20}$ A la muerte de Melzi y sus herederos, los manuscritos pasaron a manos del escultor Pompeo Leoni, de Arezzo, entre 1582 y 1590, quien los desmembró en varios cuadernos y los reagrupó en grandes volúmenes. Leoni, escultor de la corte de Felipe II, volvió a compilarlos en Madrid. Su herencia pasó a manos de su yerno Polldoro Caichi, quien, hacia 1622, vendió al Conde Galeazzo Arconati, de Milán, el gran volumen de las artes secretas de Leonardo (actual Codex Atlanticus). A su vez, Arconati lo donó, junto con otros manuscritos, a la Biblioteca Ambrosiana de Milán (1636).

Thomas Howard, Conde de Arundel, entre 1630 y 1640, adquirió el segundo gran volumen compilado por Leoni, que contenía todos los manuscritos de carácter artístico (Colección Windsor) y otro manuscrito (el actual Códice Arundel), donado por uno de sus herederos a la Royal Society inglesa. Hacia 1715, Lord Leicester adquirió el códice que hoy lleva su nombre y se lo llevó a Inglaterra.

El Códice Trivulziano (famoso por la larga lista de palabras registradas por Leonardo) volvió hacia 1750 a la Biblioteca Ambrosiana de la que había sido retirado.

Napoleón Bonaparte -en cumplimiento de las órdenes del Directorio-, confiscó el Códice Atlántico y los manuscritos de la Ambrosiana enviándolos a París (Biblioteca Nacional e Instituto de Francia). Tras su caída, el Códice Atlántico volvió a Milán, pero el Instituto de Francia conservó los otros manuscritos.

En 1876 John Forster donó al South Kensington Museum (actual Victoria and Albert Museum) tres cuadernos. Paralelamente, el bibliófilo y erudito Guglielmo Libri, proyectó editar todos los escritos inéditos Leonardo, pero sustrajo algunas páginas, que también fueron a parar a Inglaterra. Poco después el pequeño códice sobre el vuelo de los pájaros era comprado por 4.000 liras por el Conde Manzoni, quien más tarde lo cedió al ilustre leonardista Teodoro Sabatchnikof. Las hojas que habían pasado a Inglaterra fueron devueltas al Instituto y Sabatchnikof entregó el Códice sobre el vuelo de los pájaros a la Biblioteca de Turín, donde se conserva actualmente.

La Biblioteca Nacional de Madrid, en 1967, anunció el descubrimiento de dos códices extraviados de Leonardo: una parte del corpus de Pompeo Leoni, vendida en España, después de su muerte, al coleccionista madrileño Juan de Espina (1620 y 1630). Éste (1642) los legó al rey de España para la Biblioteca de Palacio que constituiría, hacia 1830, el núcleo de la Biblioteca Nacional. Se titulan Codex Madrid I y Madrid II.

El Códice Atlántico de la Biblioteca Ambrosiana de Milán fue totalmente restaurado en tiempos del Arzobispo Montini (Pablo VI) (Véase P. Galuzzi, 2019).
} 


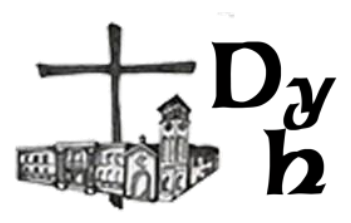

de Dios, Sermones), San Alberto Magno, Morgante, San Bernardino de Siena, G. B. Alberti, Luca Paccioli... Así lo acredita el mismo maestro, de lo cual hay constancia en diversos códices.

Concluyo con un fragmento del retrato que de Leonardo traza Eugenio Garin:

Sin embargo, [...] en muchos aspectos puede decirse que Leonardo aparece como una figura trágica. Fue un hombre solo: no tenía familia (era hijo ilegítimo), no tenía Estado propio (en el sentido de patria). Veía en torno suyo un mundo que se derrumbaba y cuyos valores espirituales eran destruidos por la fuerza bruta de acontecimientos ciegos. Y en medio de las guerras y de los trastornos que le rodeaban buscaba incesantemente una armonía imposible de alcanzar. Y por encima de todo esto, la sombra de la muerte: "Creía que aprendía a vivir, escribe, pero era a morir a lo que estaba aprendiendo". El vínculo que antaño unía al artista con su ciudad se había roto. La noción del orgullo cívico había desaparecido. El poder político en Italia había pasado a manos de oligarquías poderosas y de tiranos, a veces mezquinos, a veces hábiles. El intelectual ya no es un clericus sino un laico que se considera únicamente, y ante todo, un técnico dispuesto a ofrecer sus servicios a cualquier gobernante interesado en ellos (1974, p. 40).

\section{Benedetto Croce frente a la cuestión.}

La figura de Leonardo como arquitecto, ingeniero, inventor y artista es indiscutida, despertó, aun en vida, profunda admiración. No sucedió lo mismo, sin embargo, con la calificación de 'filósofo'. Su condición de filósofo ha despertado diversos cuestionamientos y enfoques.

No podemos soslayar la posición de B. Croce al respecto, expresada en la famosa conferencia pronunciada para el Circulo Leonardo da Vinci de Florencia, en abril de 1906. El texto fue publicado primero en el volumen Leonardo conferencias florentinas y luego en el Ensayo sobre Hegel.

Croce abre su discurso recordando a Leonardo como artista científico y técnico admirable:

[...] Leonardo no fue solamente un artista prodigioso que conjugó en su obra la fuerza y el equilibrio, la profundidad y la gracia, la exactitud de lo real y la fascinación del misterio, sino también un sutil e infatigable investigador de los 
hechos naturales y un seguro constructor de leyes científicas y de aparatos técnicos. Quiere decir que Leonardo tiene un lugar no sólo en la historia del arte, sino también en la moderna ciencia de la naturaleza (1948, p. 114). ${ }^{21}$

Y tras hacer una relación pormenorizada de los descubrimientos e invenciones de Leonardo, Croce se queja de la abundante literatura de los siglos dieciocho y diecinueve considerándolo como predecesor de todos los filósofos de la naturaleza, cuya reflexión anticipatoria se vería confirmada por los grandes científicos que le sucedieron. Así pues, cabe preguntarse si Leonardo, así como tiene un lugar en la historia del arte y de la ciencia, también lo tenga en el de la filosofía:

[...] en la tradición espiritual que, desde el gran pensamiento helénico, pasando por el neoplatonismo y el cristianismo y las controversias de la escolástica, se enlaza con el Cusano y Bruno, Descartes y Espinoza, y avanza gradualmente hasta llegar a Kant y el idealismo del siglo diecinueve (1948, p. 116).

Croce recalca que Leonardo resulta extraño a tal línea de pensamiento:

A la compañía de Sócrates y de Platón, de Aristóteles y de Plotino, de Agustín y de Tomás de Aquino; hombre de otros intereses, de otro ánimo, de otra fisonomía, de otra conversación. Él está empeñado en observar y calcular; hacia la observación y el cálculo manifiesta todo su entusiasmo (1948, p. 116).

No obstante, es de advertir que la aspereza de Croce responde a la polémica que venía manteniendo con el positivismo, y sus argumentaciones van dirigidas a desbaratar los fundamentos del mismo.

En efecto, B. Croce, se apresura a declararse abogado del diablo en la causa histórica de la ubicación del pensamiento de Leonardo.

Porque esas conferencias fueron, en su totalidad, manifestaciones del actual culto a Leonardo, quería reaccionar al tratar con el tema que se me asignó y ser un tanto abogado del diablo. Digo esto, para que se entiende la entonación de mi discurso (1948, p. 117).

\footnotetext{
${ }^{21}$ La traducción es nuestra.
} 


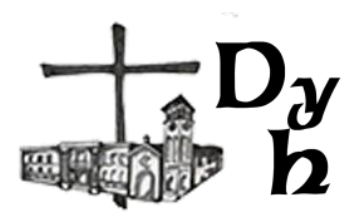

Sin embargo, el filósofo napolitano no deja de reconocer que, teniendo en cuenta el nexo histórico entre el florecimiento de la ciencia y el de la filosofía, Leonardo "[...] debe ser, por eso mismo, ubicado entre los promotores indirectos de la filosofía moderna; y hasta podrá ser llamado, si prefieren, por metonimia, filósofo". Otra cosa sería, para Croce, que esta denominación fuera tomada en sentido propio, pues en tal caso, se correría el riesgo de confundir "la materia de la filosofía con la filosofía, la actividad con la teoría de la actividad, el hecho con la conciencia del hecho" (1948, p. 116).

Los filósofos instan a la introspección, al propio conocimiento, a la búsqueda del pensamiento, a "no salir de sí, noli foras ire, en el hombre interior habita la verdad". Leonardo, en cambio, desea foras ire, anhela la posesión del mundo externo. $Y$ mientras que:

los filósofos celebran el poder del espíritu, él celebra la de los cinco sentidos y se podría decir que lo que verdaderamente adora no es el Espíritu, sino el Ojo: el más noble, el más digno de los sentidos, 'ventana del cuerpo humano' por la cual el alma especula y goza la belleza del mundo', y por la cual se contenta con la humana cárcel' (1948, pp. 116-117).

Leonardo no se canse de alabar las virtudes del ojo y casi lo coloca por encima de la naturaleza y, por lo tanto, exalta el valor de la experiencia o lo que es mejor, del conocimiento del fenómeno.

Croce consigna la manía por dividir la historia del pensamiento entre aquellos que tratan de buscar en la historia de la filosofía dos corrientes diversas, paralelas y enfrentadas entre sí, que atraviesan el mundo moderno: la empirista y naturalista, y la racionalista e idealista. En la primera ubican a Leonardo, Galileo y todos los científicos italianos, remontándose hasta la Magna Grecia, lo cual constituiría un orgullo para el pensamiento italiano en contra de las fantasías extranjeras, acomodando a los filósofos dentro de la clasificación. Según ésta, Leonardo estaría entre los filósofos naturales.

También rechaza Croce la denominación de "uomo universale" con que se apoda a Leonardo, cuando esta denominación significa 'completo', pues ello abogaría por un reconocimiento de la condición de filósofo. Y es que la 
versatilidad apreciable en Leonardo, aun siendo propia de los artistas de su tiempo, en él se potencia y, despierta en todos nosotros tal asombro y maravilla que, al no saber cómo expresarla, se recurre al adjetivo 'universal'.

Por otra parte -y ello no es de poca monta - afirma que los espíritus propiamente originales estuvieron y están absortos por una sola actividad. Leonardo sería, por tanto, una excepción a la regla y entre los contados nombres que lo acompañarían se contarían los de Goethe, Leibniz y Hegel, principalmente.

Como consigna el estudioso de la Universidad de Messina, Leonardo Gaetano Giandoriggio:

El filósofo napolitano se centra en la importancia del rol que el movimiento naturalista ha jugado en el desarrollo de la historia de la filosofía moderna. Tal corriente de pensamiento, en efecto, nacida también como reacción a rigidez de la lógica escolástica y a sus mecanismos exteriores, ha tenido un doble efecto positivo sobre la filosofía de su tiempo (Giandoriggio, 2017, pág. 86) ${ }^{22}$.

Partiendo de la concepción idealista de Croce, es natural que se le niegue a Leonardo la condición de filósofo. Pero no olvidemos que el concepto de filosofía que esgrime no es el mimo que usaba con antelación al siglo diecinueve —tras Hegel—, cuando, como marca Geymonat la filosofía abandona ciertas áreas del saber para dejárselas a las ciencias positivas.

\section{La revisión de G. Gentile}

En su conferencia "Leonardo filósofo" (1919, pp. 207-234) acerca de si puede calificarse de filósofo a Leonardo, G. Gentile se apresura a mostrar varias definiciones del tipo del filósofo para mostrar que según cualquiera de estos no puede considerárselo filosofo:

1. El autor de libros que intentan solucionar algún problema filosófico.

2. Quien, como Sócrates, con su enseñanza viva haya suscitado una escuela de pensamiento. La filosofía del s. XVI ignora su nombre.

\footnotetext{
${ }^{22}$ La traducción es nuestra.
} 
3. Aquél que, sin escribir ni enseñar una doctrina, si bien no se ocupa de cuestiones filosóficas, concentrándose en el ser atormentado por el misterio del ser. L. tubo múltiples intereses.

4. El que, advirtiendo las muchas contradicciones, trata de conciliar las contradicciones y restituya la paz interior. En Leonardo no se muestra preocupación por la consolación de la filosofía.

5. Cuando descubrimos los angustiosos problemas que nos acucian preguntamos por cómo debemos vivir, no tiene respuesta alguna.

Gentile, tras haber enfrentado a Leonardo con las cuestiones teoréticas y prácticas con las que tropieza el filósofo, constata siguiendo el hilo anterior, que Leonardo no ha dejado obras filosóficas, no ha vivido dominado por intereses filosóficos, ni ha resuelto ninguno de los problemas que preocupan a los filósofos. Claro que tampoco lo han hecho Machiavelli y Galileo, en cierto modo emparentado con él, y sin embargo, aparecen en las historias de la filosofía. Por lo cual se plantea si la filosofía debe reducirse a una concepción profesional limitada a los profesores o escritores de temas filosóficos. En tal caso, deberían rechazarse nombres como los de Dante, Miguel Ángel, Manzoni, Leopardi, quienes carecerían de filosofía alguna. Con lo cual piensa, "la filosofía dejaría de ser filosofía, concepto sintético o como habría dicho Platón, sinóptico de la realidad" (1919, p. 3).

$Y$ he aquí una importante distinción: en cada arte o disciplina hay maestros y discípulos. "En filosofía, en arte y en religión - dice Gentile-los maestros son pocos, pero alumnos somos todos" (1919, p. 4). El mensaje filosófico está destinado a todos. Los que en filosofía fueron maestros, como Platón, se dirigieron al género humano, a aquello que todos compartimos.

a los doctos e indoctos, a los grandes crecidos en la cultura y la meditación, y a los humildes, a los simples, a los párvulos maestros y alumnos en una común y casi elemental y o sea fundamental y esencial, humanidad. Por lo cual, si bien Platón es uno, todos podemos leerlo y, por lo tanto, todos platonizamos (cada uno a su manera, como lo demuestra el gran número de interpretaciones) (1919, p. 4). 
Se puede no ser maestro en filosofía y no por ello quedar fuera de la misma. Leonardo, como Dante, no fue maestro en la filosofía. Pero ello no quita que ambos pesaron y vivieron de acuerdo sentir filosófico. El poeta Dante, es filósofo dentro de su poesía y Leonardo dentro de su arte.

Leonardo, artista y científico (naturalista y matemático) dentro de su arte y su ciencia quiero decir que se comporta como artista y científico frente al contenido filosófico de su propio pensamiento, que no desarrolla por tanto en adecuada y congrua forma filosófica, pero intuye con la genialidad del artista y afirma con el dogmatismo del científico. Su filosofía, en este sentido, no es un sistema, sino la actitud de su espíritu (1919, p. 4).

Según el investigador mesinense Gaetano Giandoriggio:

[..] la referencia a Leonardo y al reconocimiento del carácter filosófico de su pensamiento, y sobre todo a las relaciones entre algunas de sus ideas y las teorías propias de la filosofía moderna, parece más clara; es parte de esa operación de historiografía filosófica a la que Gentile dedicó sus esfuerzos, en un intento por recuperar una tradición original dentro del pensamiento italiano, que, sin discontinuidades ni saltos, a los ojos del filósofo, siempre permaneció viva y activa.

En conclusión, para G. Giandoriggio, las diversas perspectivas de Croce y de Gentile se fundan en intereses y razones diferentes:

Gentile, al encontrar en Leonardo, $-\mathrm{y}$ en las otras grandes figuras del Renacimiento-, muchas de esas ideas que serán centrales en la historia de la filosofía posterior, trató de llenar los vacíos que la historiografía filosófica había atribuido a menudo al desarrollo a la historia del pensamiento italiano; Croce, por su parte, a través de la "devaluación" de Leonardo — asumido como modelo del cientificismo moderno- intentó oponerse a la acción invasora del positivismo, reaccionando a la operación de apropiación que este último estaba llevando a cabo respecto de la tradición filosófica italiana.

Por tanto considera que: 
Las de Croce y Gentile, en suma, son dos actitudes radicalmente opuestas - una destinada a demoler el mito de Leonardo como precursor del cientificismo moderno-la otra empeñada en hacerlo reingresar en el surco de la propia tradición, reconociéndole profundidad especulativa- que, en el fondo, convergen en la centralidad de la tradición cultural italiana (Giandoriggio, 2017, p. 97).

\section{El aporte de Jaspers}

En el vivacísimo texto Leonardo como filósofo, de 1953, Karl Jaspers nos descubre las peculiaridades de las reflexiones del eminente florentino.

No se detiene Jaspers en argumentar acerca de si Leonardo fue o no un filósofo, sino que prefiere, más bien, seguir sus intereses, escudriñando los numerosos y diversos escritos a disposición.

En efecto, tras recordar los diversos e ilustres estudiosos de Leonardo, Jaspers anuncia que se propone examinar: su conocer, el contenido de dicho conocimiento, y "el ejercicio de la pintura como forma vital de ese conocer". Todo lo cual conduce a determinar "en qué cosa estribe peculiar grandeza de Leonardo, la cual, no permita considerar por separado al investigador, al artista, al investigador y al filósofo" (1956, p. 14).

"Encontramos en Leonardo muchos pensamientos filosóficos tradicionales" (1956, p. 14), constata. "Se ha comprobado ampliamente el origen de sus ideas", "fue un gran lector", apunta (1956, p. 64). Según Jaspers:

En Leonardo se dan elementos procedentes del escalonado cosmos aristotélico del movimiento; asimismo otros de la concepción estoica del universo como combinación de fuerzas ordenadas lógicamente; también algunos de la imagen materialista del mundo de Demócrito y Lucrecio. Hay muy poco de la división platónica entre el mundo y la trascendencia y casi nada del espíritu neoplatónico, en la medida en que éste, según la idea del mundo animado, no contenga pensamientos de carácter estoico (1956, p. 65).

Pero también reconoce Jaspers que:

La forma en que desarrolló su filosofía, lo distingue [...] de los filósofos propiamente dichos" (1956, p. 85). Leonardo se distingue de aquellos grandes 
creadores de sistemas en que no pertenece a ninguno determinado; se vale de todos los sistemas como simple medio expresivo $(1956$, p. 85$)$.

Jaspers observa que, para Leonardo, el conocer supone ver y ejecutar: ojo y mano. La vista se impone sobre toda otra percepción, siendo preferida pues nos ofrece el mayor y más acabado conocimiento de las cosas.

Leonardo hace el elogio de la vista. Engaña menos que ningún otro sentido. Refleja todas las obras de la naturaleza. Sólo con los ojos podemos gozar de la belleza del mundo. Por la visión de las cosas se resigna el alma a permanecer en la cárcel del cuerpo (1956, p. 15).

Como Croce, Jaspers se detiene en aquel encomio de la vista que compone Leonardo, pero a diferencia del filósofo napolitano, que resalta en él la experiencia y el fenómeno, Jaspers lo completa rescatando el concepto de ejecución manual. Por eso mismo, si bien si todo è prima nella mente del suo speculatore, e non pò pervenire alla sua perfezzione senza la manuale operazione (Tratado de la pintura, §33, 157).

Lo, visto por los ojos, sólo cuando es reproducido por la mano se hace claro y visible.

Así como la mano piensa sin palabras al moverse, mientras realiza la disección de un organismo del mismo modo obra cuando dibuja y hace visibles los diseños de la fantasía, la cual crea lo que no podía encontrarse de antemano en la naturaleza. Tal modo de pensamiento, que no consiste en conceptos sino en las significaciones de líneas, formas y figuras es el conocer visual activo (1956, p. 16).

La mano, pues, muestra lo que vemos o soñamos. Lo que el espíritu contempla, la mano lo completa. De tal modo que el pintor visibiliza acabadamente todo lo pensable sin recurrir a conceptos. Lo cual le permite hablar de la "ciencia de la pintura".

La tarea de la pintura no es servil, como se ha pretendido: interviene en el conocimiento. "De suerte que, para Leonardo, el conocer como tal es al propio tiempo ver y hacer, es visión intelectiva y percepción reproducida por obra de la mano" (1956, p. 16). 


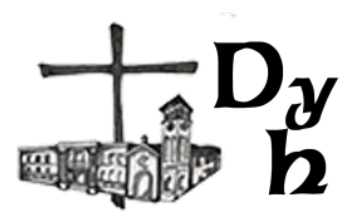

Para ello hay una actividad intelectiva que valiéndose de la matemática detiene el caos fluyente de lo sensible, y la penetración en lo particular

Tampoco este proceso es un hecho pasivo, sino que para hacer verdaderamente visible se requiere de la actividad intelectual. Necesita de la matemática que ofrece una estructura a lo sensible siempre fluyente y caótico. La matemática es la base científica de la que se vale la pintura.

Leonardo piensa en una matemática enteramente gráfica de lo visible, puesto que: "Por matemática entiende todo orden y toda legalidad accesibles al ojo" $(1956$, p. 17).

Ahora bien, a ello hay que agregar "la penetración en lo particular, en los infinitos detalles de la visión de lo real" (1956, p. 17). Así, es menester refrenar la prisa para no omitir ninguno de los tantos pormenores que la realidad ofrece. Nada de prisa, si queremos conocer y reflejar el espíritu divino contenido en la naturaleza.

Al dar al arte jerarquía de órgano de la filosofía, Leonardo se relaciona menos que aquellos [filósofos] con las sistemáticas construcciones conceptuales y con la lógica racional; se relaciona, en cambio, con la lógica filosófica concreta y con una consciente visión de la vida (1956, p. 85).

Pero eso no es todo. Habrá que hacer visible lo invisible y profundo de lo real. De aquí el empleo del claroscuro.

Jaspers interpreta lo inacabado de las obras de Leonardo como algo necesario:

Cuando lo que lo que está a la vista se quiebra o permanece inconcluso, la intención buscada se concreta. Cuando se torna impreciso lo que no alcanza a ser percibido con los ojos, se vuelve, empero, elocuente (1956, p. 23).

En todo, Leonardo quiere mostrar el espíritu en lo corpóreo.

El universo quiere ser conocido y amado, pero en forma silenciosa y sin tener que prodigarse en respuestas. La actividad incesante de Leonardo responde a 
esa incondicionalidad de contemplar el mundo y de reflejarlo en el- espíritu, .con ayuda de la fantasía (1956, pp. 102-103).

Jaspers resalta en Leonardo una unidad en sus intereses y obra por la cual merece ser llamado filósofo.

entendiendo la filosofía no como una disciplina científica, no como una doctrina, sino como un conocimiento universal de uno mismo que se hace consciente siguiendo una guía $y$, por tanto, como una forma vital de la existencia humana que encierra en sí misma el conocimiento (1956, p. 84).

Concluye Jaspers:

Lo moderno en Leonardo, aquello que lo distingue de todos los filósofos de la Antigüedad y del Cristianismo es su afán de seguir los fenómenos sin considerarlos como subordinados fundamentalmente a lo ya conocido, sino como algo siempre nuevo, y también su disposición de no dar nunca las cosas por terminadas y la constante actividad de su espíritu, inquieto por lograr una concepción fundamental de la piedad universal, que tenga su centro en la realidad de lo particular y que disfrute del infinito goce de la visión, encerrándolo en una serena tranquilidad (1956, p. 85).

\section{Epílogo de Leopoldo Lugones}

Como colofón, hemos elegido la conferencia pronunciada por el poeta argentino Leopoldo Lugones, en el teatro Colón de Buenos Aires, el 30 de mayo de 1919, en ocasión del cuarto centenario de la muerte de Leonardo.

Es la suya una aproximación empática a la figura del genio florentino. Cierto que, al leer esta versión de 1925, notamos la distancia respecto de la sintaxis y la profusa adjetivación del poeta que manifiesta el gusto de un estilo de época ${ }^{23}$. Y también deberemos abstenernos de parar en las no tan veladas simpatías por los nuevos aires que pululaban en la atmósfera peninsular. Así veremos surgir, al ritmo de su pluma encendida, la figura de un renacentista innovador, sensible y rebelde respecto de todo lo que lo ligaba al mundo medieval, asido a un paganismo humanista y libertario.

23 Recordemos la apreciación de Borges acerca singular importancia de Lugones la en las letras argentinas, pero también de su tendencia al juego verbal. 


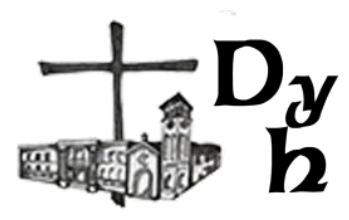

En esta memorable conferencia, Lugones traza un retrato espiritual de Leonardo en un lenguaje ricamente poético sin descuidar los fundamentos biográficos - para lo cual sigue a Vasari-, ni el cotejo, cuando se refiere a los aportes científicos, con los desarrollos posteriores.

Lugones describe plásticamente la figura de Leonardo:

Era de verlo con su traje peculiar, pues él mismo se había hecho su moda, gallardeando la antojadiza montera y el rosado blusón, para mejor resalto de los ojos suavísimos, la nariz escultural, la melena precozmente encanecida y las barbas fluviales, como si la palabra armoniosa se le estuviera visiblemente deshojando en una mansedumbre de lirios pensativos; las manos lentas y corteses, en un ademán que ennoblecía la pausa filosófica; sobresaliente el garbo con aquel desembarazo esbelto de los pinos natales; arrogante el paso y como blandido por la fibra del jarrete montañés; único por el tipo que humana y divinamente generalizaba la luz intelectual; fuerte hasta lo asombroso con aquel vigor que partía la herradura de un potro paduano entre los dedos formidables, y hermoso como el libre amor del cual había nacido.

Monta, nada y esgrime a la perfección como los duques de los castillos. Su conversación es más artística que su propia pintura.

Realiza el tipo más completo de hombre que se conozca, y viola al nacer la legitimidad. Divergente hasta en los detalles orgánicos, es zurdo y escribe habitualmente de derecha a izquierda con el mismo tipo caligráfico del griego que no sabe $(1925)^{24}$.

Lugones ubica al ilustre personaje en el paisaje citadino de su tiempo:

Leonardo, y esto es decirlo todo, constituía un espectáculo de Florencia. Para representárnoslo, precisaremos reconstruir mentalmente la calle medioeval con la viva pintura de sus casas en que se gloriaban el azul, el bermellón y el oro, repetidos por los trajes correspondientes y constituyendo una armonía total cuya negación define el neutro gris de nuestras predilecciones, vacilante entre el frío orgullo del mármol y el negro ceremonioso que impuso el despotismo en la lúgubre persona de Felipe II.

\footnotetext{
${ }^{24}$ Dada la consulta de la versión online, en lo que sigue del texto de Lugones, no nos es posible citar por página.
} 
Pero Lugones, al describir a Leonardo y su obra no se vale solamente de complejas metáforas, sino que hace gala de precisos conocimientos científicos.

Así se expresa:

Aplicando probablemente las Ilamadas «series de Fibonacci,» su matemático tocayo del siglo XIII (Leonardo de Pisa), descubre la filotaxis o ley de distribución de las hojas en las plantas, que sólo cuatrocientos años después completaría el botánico Schimper. Estudiando los remolinos del polvo y del agua y la disposición de las nubes, da con la trascendencia de la línea espiral, que está igualmente en la filotaxis, y cuyo desarrollo contiene la descripción primordial del movimiento y el origen de la forma. Artísticamente emplea el caracol del amonite en el peinado decorativo y en el adorno de tal cual yelmo que coronan sus cabezas de estudio, y aplica esa forma primordial a la ideación de un eje ascendente. La profundidad de sus estudios anatómicos en los diversos órdenes de la zoología puede inferirse por este detalle magistral: Leonardo fue el primero que propuso la división de los animales en vertebrados e invertebrados. Otra vez, reflexionando sobre la propagación de los sonidos, anticipa nuestra teoría ondulatoria, en la cual comprende ya el magnetismo y hasta el pensamiento humano.

Respecto de las invenciones de Leonardo como ingeniero, Lugones se detiene en la Carta de presentación a Ludovico el Moro:

Puedo construir carros cubiertos, seguros e indestructibles, que llevando artillería y penetrando por las filas contrarias romperán las tropas más sólidas». He ahí el tanque de las recientes batallas. Sostiene que ha descubierto la navegación submarina, o, si se quiere, la escafandra del buzo, pero que no lo publica "por maldad de los hombres que de ello se servirían para asesinar en el fondo de los mares, abriendo los navíos y sumergiéndolos con su tripulación". Estudia el aeroplano hasta concebirlo enteramente parecido a algunos de nuestros primeros aviones, salvo el motor en que el misterio del vuelo se le escapa. En cambio, ha llegado a formar de cierta cera pájaros que echa a volar por el aire.

Músico profundo, inventa una lira de plata que ha cincelado en forma de cabeza equina, arrancándole una maravillosa sonoridad. 


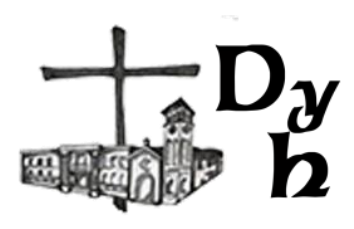

Y conjetura:

Para los suyos, aquellas invenciones y ocurrencias con que se les acercaba el prodigio, fueron locuras brillantes o sospechosas de brujería. Aparentan creer más en su pintura que en sus matemáticas. Pero viene Cantor, el gran historiador de estas ciencias en el siglo XIX, y reconoce a Leonardo como uno de los gigantes que en el siglo XV las renovaron.

Ya transforma aquellos pantanos en prados útiles, o deriva y canaliza ese río; ya discurre el buque de ruedas como el salvavidas, el paracaídas como el aeroplano; y trépanos para buscar las aguas subterráneas, y telares para la seda, el lino, la lana y el cáñamo; y grúas, y laminadores, y sierras, y lámparas de doble tiraje, y ejes y cojinetes de rozamiento mínimo, y cañones de cargar por la recámara.

Pues todo aquello lo lleva, artista supremo como es, a la trascendencia de las formas naturales por el camino de la belleza.

En cuanto a los aportes a la pintura, Lugones enumera varios rasgos. Especial uso de la perspectiva:

[...] el cuadro perspectivo de Leonardo, no intenta, según había sucedido hasta él, traernos el paisaje o la figura como nacidos en la tela, sino abrirnos una ventana sobre la figura o sobre el paisaje. $Y$ no existiendo en esa abertura realidad material, tiene que ser una puerta del alma.

El claroscuro, al que considera una "revalorización de la luz".

[...] en el cuadro leonardesco la luz vale más que el color. Este ha podido ennegrecerse, mientras la impresión luminar persiste, y aun adquiere una penetración más misteriosa, como cuando naturalmente se disuelve en la translucidez de uva azul que trae la noche.

Se detiene luego en la importancia de la expresión y la expresión, manifiesta en la sonrisa que lo distinguiría de "los pintores florentinos antecesores y contemporáneos suyos", a quienes considera principalmente "decorativos". 
La tercera cosa es la expresión, definida con mayor agudeza por la sonrisa. Este gesto encuéntrase ya en las vírgenes del siglo XIV, y Leonardo tomólo sin duda del femenino que pintaba su maestro Verrocchio, así como ciertos rasgos decorativos de escultura orfebrada; pero él le puso la complejidad inquietante que nosotros llamaríamos sugestión pasional, transformando la sonrisa, de rasgo inocente, en coquetería suspicaz y peligrosa. La sonrisa de la Gioconda es toda la mujer.

Y siempre por encima de todo, el "afán de perfección", más allá del arte, que Lugones critica, y al que califica de "tentativa de semidiós" que "revela en lo inconcluso de la realización el aletazo de un numen caído".

\section{Bibliografía}

Blasco, F. (2019). Luca Pacioli, el amigo matemático de Da Vinci amante de la divina proporción. ABC ciencia, Madrid, 27/5/19.

Croce, B. (1948). Leonardo filosofo; Conferenza, en Saggio sullo Hegel seguito d'altri scriti sulla storia della filosofía. Laterza, Bari, pág. 207-234.

Recuperado de http://www.franuvolo.it/sito/doc/Leonardo-in/016.pdf

Casu, S. (2013). Il Tratato della Pitura di Leonardo da Vinci; Tradotto per tutti in italiano moderno. E-book. www.macroedizioni.it. Recuperado de http://www.desideriocrea.org/leonardodavinci/downloads/Simone_Casu_ Leonardo_Demo.pdf

Galuzzi, P. (1974). La extraña aventura de los manuscritos de Leonardo. Correo de la UNESCO, octubre 1974, año XXVII, pág. 5-12. Recuperado de file://C:/Documents\%20and\%20Settings/PC/Mis\%20documentos/Downl oads/074877spao.pdf

Garin, E. (1974). Leonardo y el mundo tumultuoso del Renacimiento. Correo de la UNESCO, octubre 1974, año XXVII, pág. 40-52.

Recuperado de https://es.unesco.org/courier/octobre-1974/extrana-aventuramanuscritos-leonardo

Gentile, G. (1919). Leonardo filosofo; Conferenza, en Nuova antología. Roma, a 54 fasc. 1137, pág. 232-250. Recuperado de http://www.franuvolo.it/sito/doc/Leonardo-in/081.pdf 


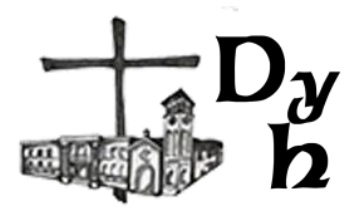

Giandoriggio, G. (2017). Leonardo filosofo di Croce e di Gentile. II Pensiero Italiano Rivista di Studi Filosofici. Vol. 1, Numero 1. Publicación online. Recuperado de file://C:/Documents\%20and\%20Settings/PC/Mis\%20documentos/Downl oads/1593-5032-1-PB\%20(7).pdf

Jaspers, K. (1956). Leonardo como filósofo. Bs. As.: Sur.

Lugones, L. (1925). Elogio de Leonardo; Conferencia leída en el teatro Colón el 30 de mayo de 1919 para el IV centenario. Recuperado de https://es.wikisource.org/wiki/Elogio_de_Leonardo 